INTERNATIONAL JOURNAL OF RESEARCHES IN BIOSCIENCES, AGRICULTURE AND TECHNOLOGY

(C) VISHWASHANTI MULTIPURPOSE SOCIETY (Global Peace Multipurpose Society) R. No. MH-659/13(N) www.vmsindia.org

\title{
STUDY OF PISCEAN TAPEWORM AT RATNAGIRI DISTRICT OF MAHARASHTRA STATE, INDIA.
}

\author{
V. B. Supugade ${ }^{1}$, R. G. Patil ${ }^{1}$ and J. S. Dhole ${ }^{2}$ \\ 1,Lal Bahadur Shashtri College Satara (M.S.) India. \\ 2,Dr. B.A. Marathwada University Aurangabad. (M.S.) \\ supugadevb26@gmail.com
}

\begin{abstract}
The present study deals with diversity of Piscean tapeworm were studied for taxonomic characteristics in relation with geographic distribution and host species in freshwater fishes from Maharashtra state. During the present study (July 2012- June 2014) total 6 tapeworm were recorded. All these genera differ from each other in general topography of taxonomy. During the present study 479, marine fishes were examined, in which 287 fishes were infected with five genera of tapeworm parasites among these family Onchobothriidae are highly diversified later on Tentaculariidae, Lecanicephalidae respectively. The present studies are helpful for the status of diversity of Piscean tapeworm from Ratnagiri district.
\end{abstract}

Key - Words: Piscean, Tapeworm, Ratnagiri District.

\section{Introduction:}

Fisheries are important for the Indian economy as it provides employment opportunities, is a source of nutritional food and foreign exchange earnings. Currently, India's total annual fish production is approximately 5.65 million tons (Inland-2.8 and Marine-2.83 million tons) from which India has an estimated potential of about 8.4 million tons (Inland 4.50 and marine 3.90 million tons) but fish farming remains a high risk investment, due to many diseases including parasitic infections. The common parasites of fishes causing the economic losses includes the helminth parasites like Phoreiobothrium (Linton, 1889), Polypocephalus (Braun, 1878). However, very little is known about the parasitic fauna of fishes of the India in comparison with the information available from other regions of the continent. The strict dependence of the parasite on its host and the exploitation of the latter by the former provide a useful research model in the field of ecology and evolutionary biology. Several investigations have studied helminth parasites of freshwater fishes through the work of these investigation concerning the survey, population dynamics, host specificity, organ specificity (Jaywant Dhole et al., 2010). Therefore one objective of this study was to determine variation in intensity of infection and the second was to determine variation in parasite fauna with the diet of the host, variation in infection with the habitat type.

\section{Material and Methods:}

The marine fishes were collected various region of Ratnagiri district during the July 2012 to June 2014. The parasites are considerably long, preserved in $4 \%$ formalin and six of them stained with Borax Carmine, mounted in D.P.X. for taxonomical studies, while remaining for Biochemical studies. Sketches are drawn with the help of Camera Lucida and all measurements are in millimeters. The identification is made with the help of "Systema Helminthum" by Yamaguti (1961).

\section{Description:}

Nybelinia lingualis (Cuvier, 1817)

Twenty five specimens of the tapeworm were collected from the intestine of Carcharhinus dussumieri (Muller and Henle, 1839) at Harne, Bhatye, Mirkarwada, Bhagwati, Ratnagiri (M.S.) (West Coast of India) in the July 2012 to June 2014.

The worm measures about 60 in length and 0.6 in breadth, consisting of 75 segments. Scolex is medium in size, tubular in shape, measures 0.873 in length 0.461 in breadth. Scolex is divided into three parts. Anterior paras bothridialis, consists four elongated bothridia, through which four proboscides come out, and measures 0.2815 in length. Middle paras vaginalis is narrow anteriorly and broad posteriorly, it consists of four unarmed tubes, measures about 0.2330 in length. Posterior part of the scolex paras bulbosa, with four small, oval or rounded shaped bulbs which measures 0.2427 in. Proboscis sheath lies in the middle side of scolex, inside the proboscis sheath lies four tentacles, anteriorly tentacles are armed with hooks of different size. Hooks are 2-3 in number, in transverse rows. Thick hooks are long, large in size with broad base and pointed at anterior. These four proboscides measures 0.4150 in length and 0.0050 in breadth. Four oval muscular bulbs are placed in the posterior part of proboscis sheath, measures 0.1577 in 
length. Behind the posterior scolex lies a velum and it measures 0.1699 in length.

The mature segments are longer than broad, almost 2-3 times longer than broad, measures 0.9465 in length and 0.5096 in breadth. Testes oval or rounded in shape 40-45 in number scattered all over the segment except cirrus pouch region, 0.046 in length. Cirrus pouch large in size, oval transversely placed, present just anterior to the middle part of the segment and measures 0.1359 in length and 0.0679 in breadth. Cirrus is present within the cirrus pouch; thin tube like structure measures 0.1165 in length and 0.0072 in breadth, vas deferens is thin tube curved \& extend towards anterior side, measures 0.0679 in length and 0.0048 in breadth. Vagina starts from the common genital pore tubular to the cirrus pouch, curve posteriorly, measures 0.3543 in length and 0.0169 in breadth. Receptaculum seminis is tube like measures 0.262 in length and 0.0218 in breadth. Ootype large oval measures 0.0194-0.0291 in diameter. Genital pore is marginal, oval cap like measures 0.0043 in length and 0.0024 in breadth. The ovary is bilobed elongated measures 0.2038 in length and 0.0218 in breadth. It is placed in the posterior part of the segment. Vitellaria are granular. Uterus large, tubular, elongated measures 0.6941in length and 0.0606 in breadth. Eggs are rounded 35-40 in number measures $0.121 \times 0.0169$ in diameter.

\section{Nybelinia pintneri (Yamaguti, 1934)}

Twenty eight specimens of the cestode parasites were collected from the intestine of Carcharias acutus Cuvier, 1871 at Bankot, Mirkarwada, Bhatye, Harne, Ratnagiri, M.S. (West Coast of India) in the July 2012 to June 2014.

The worm measures about 60 in length and 0.6 in breadth, consisting of 65 segments. Scolex is large in size, tubular in shape, measures 1.310 in length and 0.5218 in width. Scolex is divided into three parts. Anterior part paras bothridialis, consists four elongated bothridia, through which four proboscides come out, and measures 0.194 in length and 0.473 in width. Middle paras vaginalis is narrow anteriorly and broad posteriorly, it consists of four unarmed tubes, measures about 0.570 in length and 0.521 in width. Posterior part of the scolex paras bulbosa, with four small, oval shaped bulbs which measures 0.606 in width. Proboscis sheath lies in the middle side of scolex, measures 1.310 in length and 0.521 in width. Inside the Probscis sheath lies four tentacles, anteriorly tentacles are armed with hooks of different size. Hooks are 3-4 in number, in transverse rows. Thick hooks are long, large in size with broad base and pointed at anterior. These four proboscides measures 0.194 in length and 0.473 in width. Four oval muscular bulbs are placed in the posterior part of proboscis sheath, measures 0.521 in length and 0.145 in width. Behind the posterior scolex lies a velum and it measures 0.315 in length and 0.009 in width.

The mature segments are longer than broad, almost 2-3 times broader than long measures 0.813 in length and 0.970 in width. Testes oval in shape 30-35 in number, scattered all over the segment except cirrus pouch region, 0.043 in diameter. Cirrus pouch large in size, oval transversely placed, present just anterior to the middle part of the segment and measures 0.181 in length and 0.133 in width. Cirrus is present within the cirrus pouch, thin tube like structure measures 0.189 in length and 0.012 in width, Vas deferens is thin tube, curved \& extend towards anterior side, measures 0.157 in length and 0.007 in width. Vagina starts from the common genital pore. Receptaculum seminis is tube like measures 0.054 in length and 0.028 in width. Ootype large oval measures 0.065 in diameter. Genital pore is marginal, oval cap like measures 0.038 in length and 0.024 in width. The ovary is bilobed having 20-25 acini measures 1.079 in length and 0.339 in width. It is placed in the center just posterior to the middle part, of the segment, shell gland is rounded measures $0.022-0.027$ in diameter placed below the ootype, vitellaria are granular.

Phoreiobothrium jadhavae (Supugade et al., 2014):

One hundred twenty four specimens of the cestode parasites were collected from the intestine of Aetobatis narinari, (Muller and Henle) at Harne, Bhagwati, Mirkarwada, Bhatye, Ratnagiri West Coast of India during the July 2012 to June 2014.

The worm measures about 25 in length and 0.3 in breadth, with 44 segments. The scolex is quadrangular in shape, medium in size, somewhat narrow anteriorly and broad posteriorly, with concave lateral margines. It measures 0.85 in length and 0.081 in breadth. The scolex bears four bothridia, which are elongated, broad posteriorly and narrow anteriorly, each armed with a pair of hooks. Each bothridium is with a single, large loculum at its posterior end. The hooks are paired and bifurcated i.e. having two prongs, the outer 
prong $\&$ inner prong. Each hook bears a handle, which measures 0.007 in length and 0.002 in breadth.

The scolex is followed by a short neck, without spines and measures 0.068 in length and 0.027 in breadth. The mature segments are broader than large with convex lateral margins without spines. These segments vary in length. The segment measures 0.074 in length and 0.092 in breadth. Testes 236in number, oval, pre-ovarian and measures 0.004 in diameter. These are distributed from ovary to the anterior margin of the segment. The cirrus pouch is oval, elongated in shape. The cirrus is thin straight slightly curve at anterior side measures 0.022 in. The cirrus is short, lies inside the cirrus pouch. The vas deferens is short tube runs anteriorly in the medullary part of the segment. The ovary is bilobed, lobes are medium in size with irregular margins measures 0.026 in length and 0.01 in breadth. Vagina starts from the common genital pore, antero-dorsal to the cirrus pouch elongated, thin tube runs transversely up to the middle of the segment opens into the ootype and measures 0.08 in length. Genital pores are small, oval, marginal irregular alternate, measures 0.007 in length and 0.002 in breadth. The ootype is rounded in shape, post-ovarian and measures 0.006 in diameter. The vitellaria are follicular, oval, large, single row on each side from the anterior margin to the posterior margin of the segment except the cirrus pouch region.

\section{Polypocephalus balkuae (Supugade et al., 2014):}

Twenty nine mature specimen were collected from the spiral intestine of Trygon zugei (Muller \& Henle, 1841) at Bhagwati bander Harne, Mirkarwada, Bhatye, Ratnagiri (West Coast of India) from July. 2012 to June 2014.

The worm measures about 25 in length and 0.8 in breadth, with 25 segments. Scolex is broader anteriorly and narrow posteriorly with spherical shape. It measures 0.523 in length and 0.784 in breadth. Anterior region is represented by $12-14$ tentacles, which evaginate through the central cavity and posterior region with four suckers which are oval to round in shape. The suckers measures 0.356 in length and 0.795 in breadth. The neck is short, cylindrical in shape and measures 0.309 in length and 0.503 in breadth. The mature segments longer than broad, these segments vary in length. The segment measures 0.069 in length and 0.089 in breadth. Testes are 19 in numbers oval in shape situated in the center of the mature segments measures 0.89 in length and 0.709 in breadth. Cirrus pouch is elongated, oval, measures 0.095 in length and 0.72 in breadth. Cirrus is short, measures 0.41 in length. The vagina and cirrus pouch open through a common pore known as genital pore 0.309 in length. Vagina arise from genital pore takes a turn posteriorly and opens into the receptaculum seminalis measures 0.41 in length. Vas deferens is short. Ovary bilobed, elongated laterally and placed at the posterior side of the segment measures 0.12 in length and 0.050 in breadth. The ootype is situated at the middle region of the ovary, measures 0.03 in diameter. Vitellaria are follicular. The uterus is oval in shape, broader at anteriorly and narrow posteriorly, it consists of number of eggs, which are rounded and non-operculated.

\section{Tylocephalum salunkhi (Supugade et al., 2014):}

One hundred twenty worms were collected from different places such as Bhatye, Harne, Bhagwati, Mirkarwada, Ratnagiri (West Coast of Maharashtra, India). Ninety Seven parasites were collected from intestine Trygon sephen (Cuvier, 1871) at Harne, Mirkarwada, Ratnagiri district (West Coast of Maharashtra, India) during July 2012 to June 2014.

The scolex is divided into two regions, anterior and posterior. The anterior region is somewhat oval; globular with muscular pad and posterior region with somewhat quadrangular, anteriorly conical posteriorly narrow in e. The scolex measures 0.702 in length and 0.4878 in breadth. suckers are oval in shape two are placed towards the anterior side and two are placed towards the posterior side of the scolex . The scolex followed by neck. The neck is long measures 0.407 in length and 0.164 in width.

The mature segments are longer than broad and measures 1.087 in length and 0.809 in width. The testes are large oval 16 in numbers, pre-ovarian placed towards anterior of the segments, measures 0.072 in length The cirrus pouch is oval, elongated, large, placed anterior to the middle of segments and measures 0.167 in length and 0.07 in width. Cirrus is thin, straight within cirrus pouch. The protrusible cirrus is open from the common genital pores seen in gravid segments and measures $0.19 \mathrm{in}$. The cirrus and vagina opens into the common pores. The genital pores are oval, large marginal, irregularly alternate and measures 0.03 in length. The vagina opens through the genital pores, which is long tube, 0.402 in length and forms into short tubular receptaculum seminis which measures 0.503 in 
length and reaches to the ootype. The ootype is large, oval in shape measures 0.064 in length and 0.050 in width. Ovary bilobed placed posteriorly of the segment, measures 0.21 in length and 0.16 in width. The vitellaria are follicular, tubular uterus opens and placed longitudinally anteriorly in the segment and measures 0.83 in length and 0.98 in width and contain rounded eggs.

\section{Uncibilocularis housaii (Supugade et al., 2014):}

Eighty six specimens of the tapeworm were collected from the spiral valve of Dasyatis walga (Muller and Henle, 1841) at Mirkarwada, Bhatye, Mirya, Harne, at Ratnagiri District (West Coast of India) in the period of July. 2012 to June 2014.

The scolex is almost elongated in shape with broad anterior end and narrows posteriorly and it bears four oval and sessile bothridia. The scolex measures 0.89 in length and 0.97 in breadth. The bothria measure 0.501 in length and 0.24 in breadth. Each bothridium is divided into two oval locula of which the anterior locula is larger than the posterior one. Accessory suckers are absent. Each bothridium bears a pair of bifurcated hooks. Each hook is having two prongs each pair of prong has handle measures 0.15 in length. The inner prong of the hook is larger than the outer prong.

The scolex is followed by a long neck, with measure 0.79 in length and 0.48 in breadth. The mature segments are three to four times broader than long measures 0.59 in length and 1.6 in breadth. The testes are oval in shape, preovarian and 68 in numbers, measures 0.08 in length. The cirrus pouch is large, tubular in shape measures 0.24 in length 4 and present at the anterior side of the segments. The cirrus is thin, straight measure 0.25 in length and forms vas deferens which is thin, short and slightly curved posteriorly. The cirrus and vagina opens through a common pore which is known as genital pore. The genital pores are small, marginal, irregularly alternate and measures 0.04in length and 0.049 in breadth. Vagina starts from the common genital pores vagina is a long narrow tube, anterior to the cirrus pouch, takes a curve and forms receptaculum seminis measures 0.36 in length and 0.008 in breadth. Receptaculum seminis is short tube measures 0.39 in length, which reaches to the ootype which is rounded lies in between two lobes of the ovary and measures 0.049 in diameter. The ovary is bilobed, elongated dumb-bell shaped measures 0.98 in length and 0.2 in breadth. The uterus is broad tube, straight arise from ootype in middle region of the segment, measures 0.42 in length. The vitellaria are granular placed at the both lateral sides of the mature segments except cirrus pouch.

\section{Discussion:}

The present communication $N$. lingualis comes closer to Nybelinia lingualis (Cuvier 1817) having scolex tubular, tentacles four in number, more or less in size, mature segments longer than broad and vitellaria granular but differs from shape of bothridia number of testes 40-45, Cirrus pouch Oval, shape of ovary bilobed. The present communication N. pintneri comes closer to $N$. pintneri (Yamaguti 1934) having scolex is long, tubular as against oval and short, paras bulbosa is not overlapping on paras bothridialsis as against over-lapping on each other. Testes are 30-35 in number. The present communication $P$. jadhave comes closer to P.jadhavae (Supugade et al., 2014) having shape and size of scolex number of testes and size of ovary. The present communication $P$. balkuae comes closer to P.balkuae (Supugade et al., 2014) having size of scolex, number of testes and size of mature segament. The present communication $T$. salunkhi comes closer to $T$. salunkhi (Supugade et al., 2014) having number of testes and size of mature segament, shape of cirrus pouch. The present communication U.housaii comes closer to U.housaii (Supugade et al., 2014) having size of scolex, shape of hooks, number of testes and size of mature segament.

These are minor characters, so it is not possible to erect a new species. So, it is redescribed with some additional characters that's why the worm turns $N$. lingulais (Cuvier, 1817), N. pintneri (Yamaguti 1934), P.jadhavae (Supugade et al., 2014), P.balkuae (Supugade et al., 2014), T. salunkhi (Supugade et al., 2014), U.housaii (Supugade et al., 2014).

\section{Acknowledgement:}

The author is very much thankful to the Principal of L. B. S. College Satara and Head, Department of Zoology, Dr. Babasaheb Ambedkar Marathwada University, Aurangabad (M.S.) India for providing the laboratory facilities during this work. 


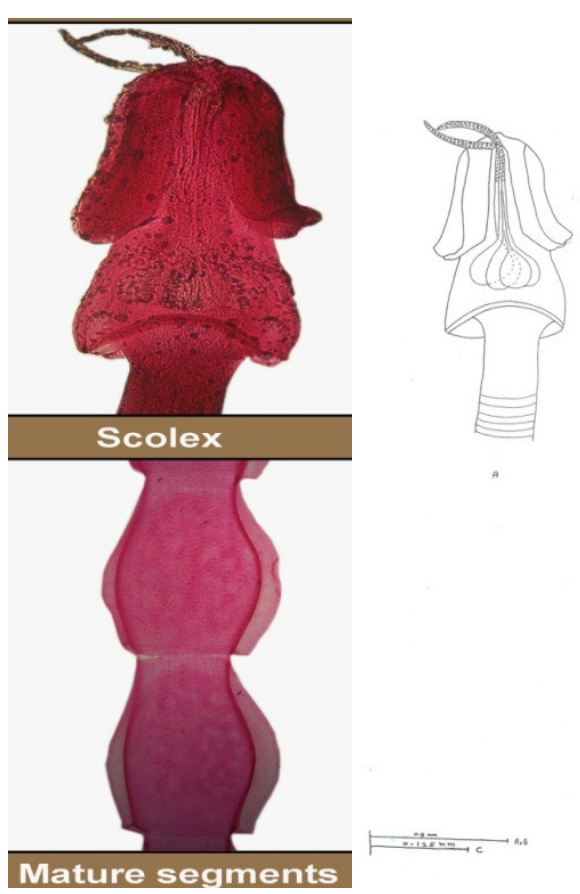

Nybelinia lingualis (Cuvier, 1817)

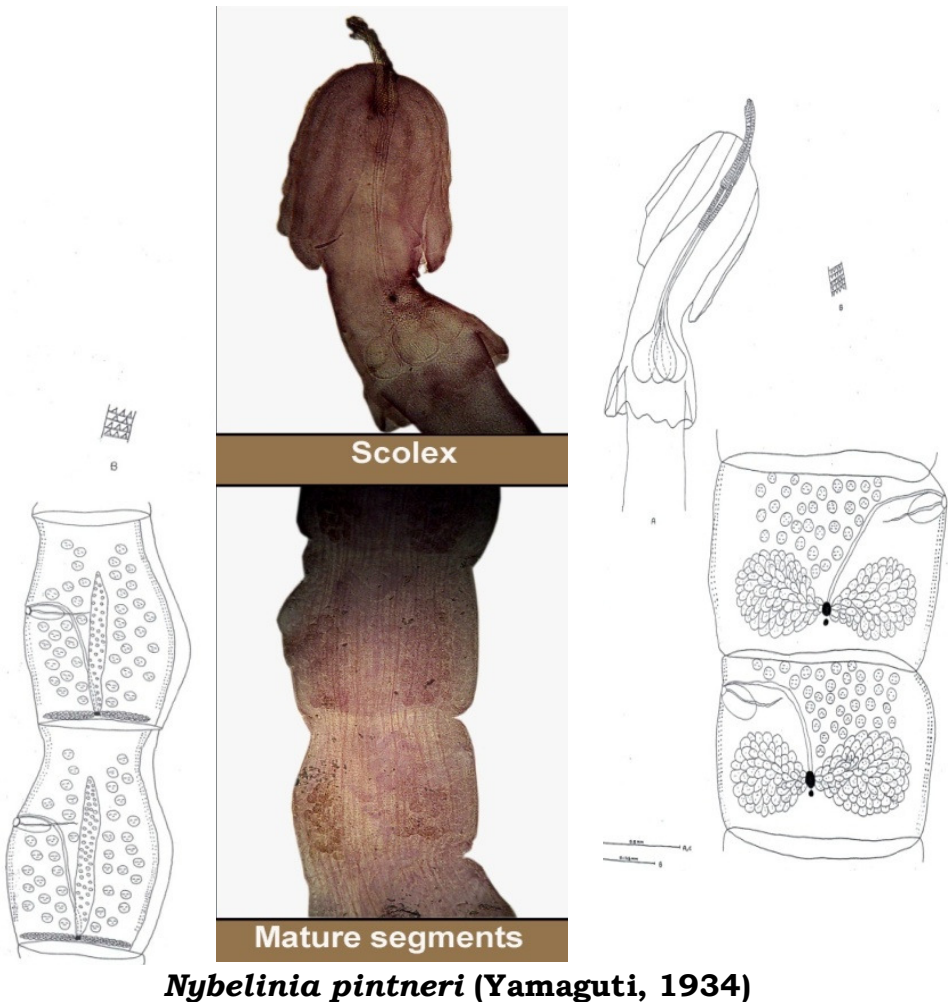

Nybelinia pintneri (Yamaguti, 1934)

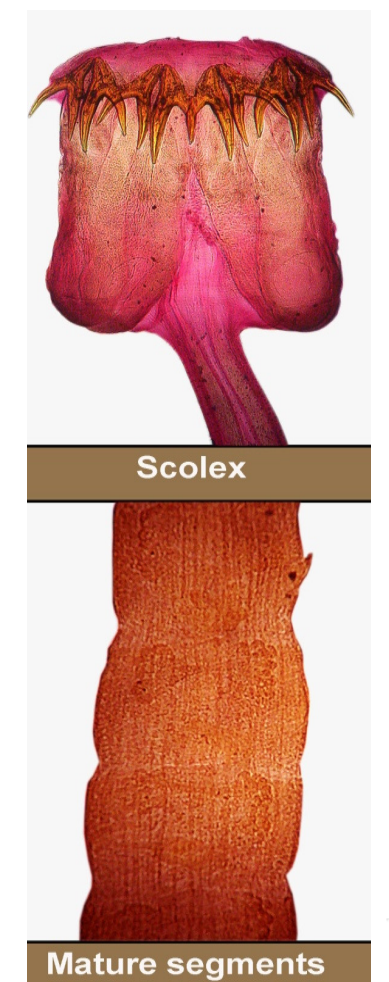

Phoreiobothrium jadhavae (Supugade et al., 2014)
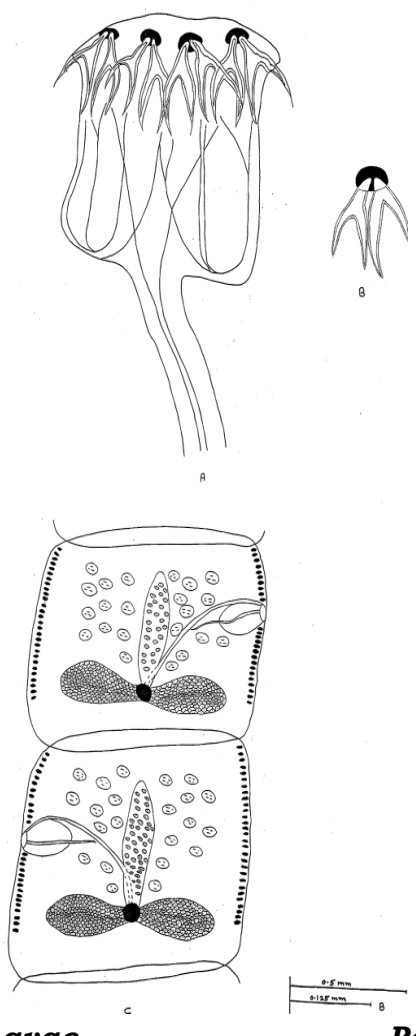

$$
\begin{aligned}
& \text { Polypocephalus balkuae } \\
& \text { (Supugade et al., 2014) }
\end{aligned}
$$
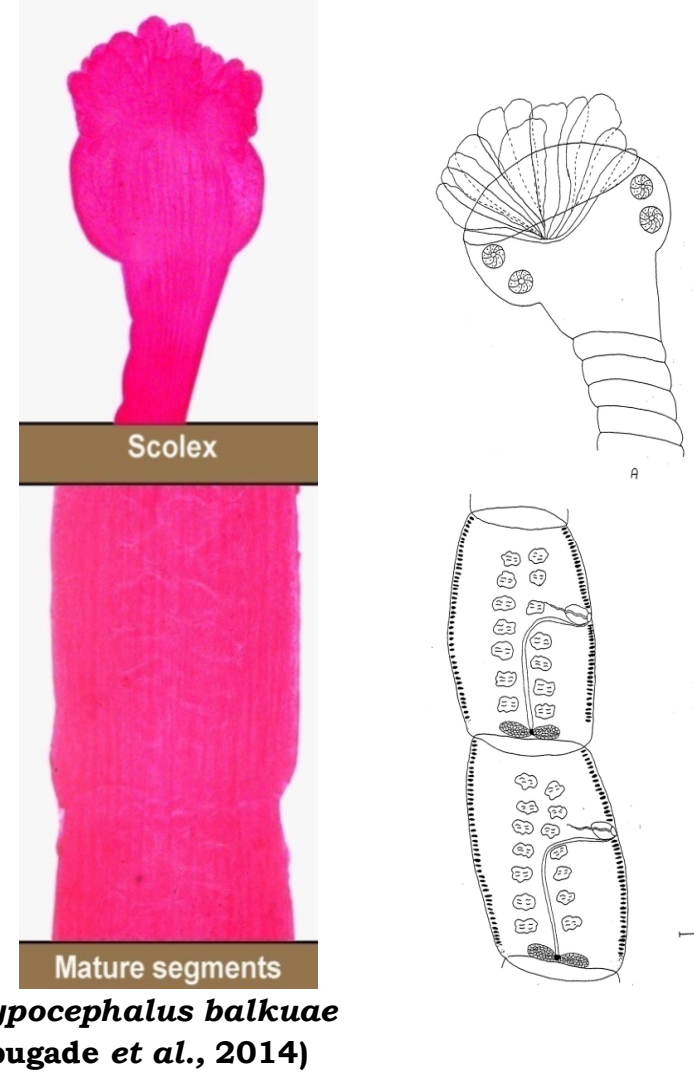


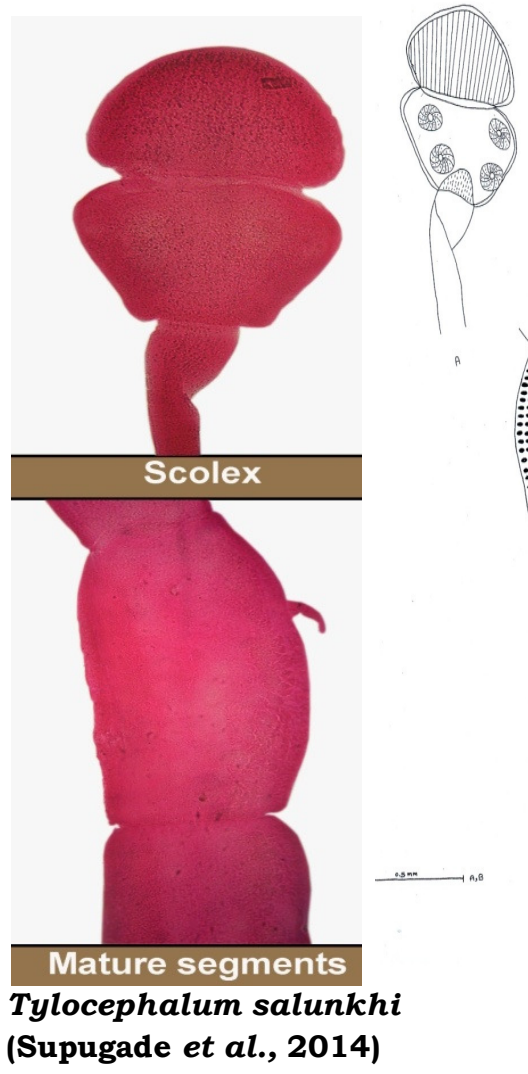

\section{References:}

Jaywant Dhole, Somnath Waghmare and Ramrao Chavan (2010): Survey of helminth parasites in freshwater fishes from ,Marathwada region, MS, India (Journal of Fisheries and Aquaculture, ISSN: 0976-9927 \& E-ISSN: 09769935 Vol 1, Issue 1, 2010, PP-01-07)

Linton, E. (1889): Notes on Entozoa of marine fishes of New England. Ann. Rep. U.S. Comm. (Fish and Fisheries for 1856 Washington, 1889, 14: 453-517).

Southwell, T. (1925): A monograph of Tetraphyllidea with notes on related cestode. (Man. Live. P. Sch. I. Trop. Med. (M.S.) no. 2: pp. 1-368).

Subhapradha, C. K. (1955): Cestode parasites of fishes of Madras coast. (Indian journal of Helminthology 7:42-132).

Supugade V. B. and J. S. Dhole (2014): Taxonomic observations of fish tapeworm Polypocephalus balkuae n.sp. From marine fish Trygon sephen at Ratnagiri District (M.S.) India. (Proc. of Nat. Conf. on Enviro.Biot. (2014) ISBN $978-81-8498-412-6$ pp. 1-5).

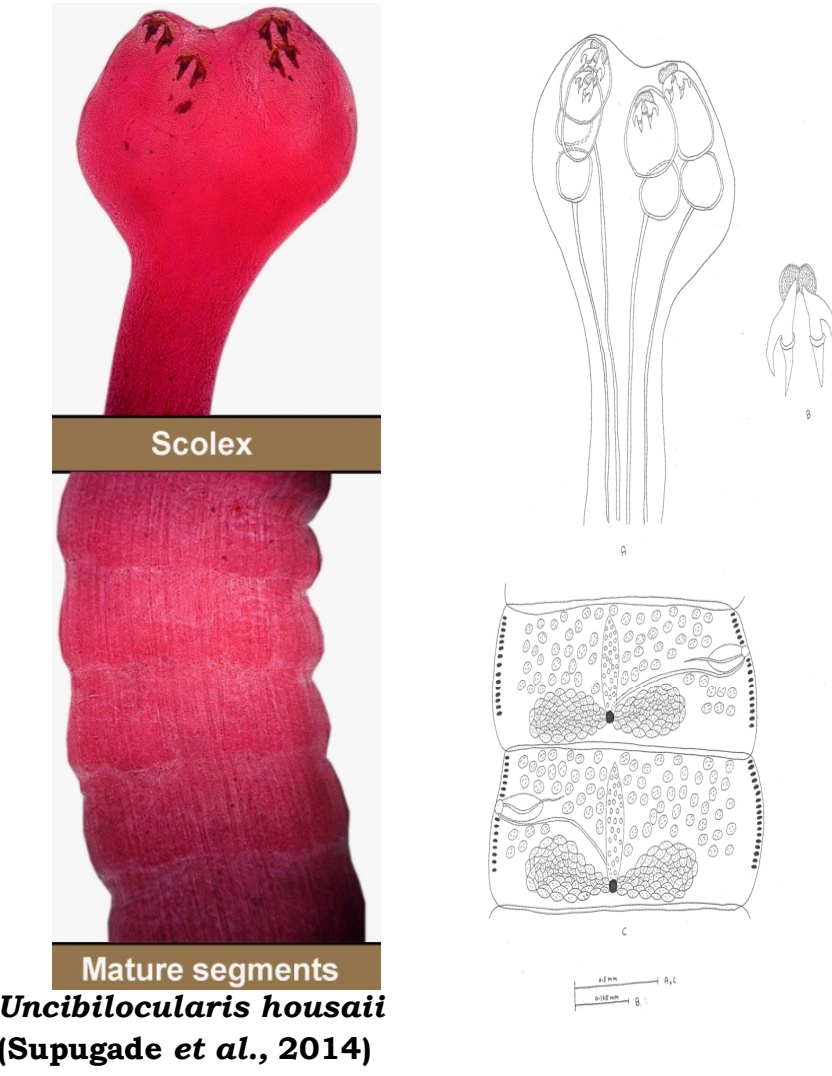

Supugade V. B. and R. G. Patil (2014): A new onchobothridaen tapeworm, Uncibilocularis housaii n. sp. from marine fish, Dasyatis walga at Ratnagiri district (M.S.), India (Proc. of Nat. Conf. on Enviro.Biot. (2014) ISBN 978 - 81 8498 - 412-6 pp. 1-5).

Supugade V. B and S. S. Patil (2014): Taxonomic evaluation of fish tapeworm Tylocephalum salunkhi n.sp. from marine fish trygon sephen at Ratnagiri district (M.S.) India. (Proc. of Nat. Conf. on Enviro.Biot. (2014) ISBN $978-81-8498-412-6$ pp. 1-5).

Woodland, W.N.F. (1930): On the genus Polypocephalus, Braun, 1878 (cestoda). (Prac. Zool. Soc. Land. 100, 342-354).

Yamaguti, S. (1934): Studies on the Helminth fauna of Japan, part 4, cestodes of Fishes. (Japan, J. Zool. 6: 1-112).

Yamaguti, S. (1939): Studies on the Helminth fauna of Japan. Trematodes of fishes VII (Jap. J. Zool. 9 (1): 35-108). 